\title{
Radiography, tomosynthesis, CT and MRI in the evaluation of pulmonary cystic fibrosis: an untangling review of the multitude of scoring systems
}

\author{
Kristina Vult von Steyern • Isabella M. Björkman-Burtscher • \\ Mats Geijer
}

Received: 26 May 2013 /Revised: 4 July 2013 / Accepted: 2 September 2013 /Published online: 25 September 2013

(C) The Author(s) 2013. This article is published with open access at Springerlink.com

\begin{abstract}
Objective The first radiographic scoring system for pulmonary cystic fibrosis was presented in 1958. Since then a multitude of scoring systems for radiography and computed tomography (CT) have been presented, recently also for tomosynthesis and magnetic resonance imaging (MRI). The aim of the current review was to analyse and compare the plethora of scoring systems for cystic fibrosis, especially regarding which scoring components are considered most important.

Methods Four scoring systems for chest radiography, one for tomosynthesis, eight for CT and one for MRI were compared regarding components evaluated and their terminology; the areas scored; scoring levels; the weighting of each component in percentage of the total score; and the calculations for the final score.

Results In most radiological scoring systems the lungs are evaluated for increased volume, bronchial wall thickening, bronchiectasis, mucus plugging, atelectasis and consolidation. In addition, for instance abscesses, bullae, septal thickening, mosaic perfusion, ground glass opacities and air trapping are evaluated in some CT scoring systems. Pleural affection and perfusion defects are scored on MRI.

Conclusions Bronchiectasis alone, or in combination with mucus plugging, is given the highest weighting in most scoring
\end{abstract}

K. Vult von Steyern $(\bowtie) \cdot I$. M. Björkman-Burtscher $\cdot$ M. Geijer Center for Medical Imaging and Physiology, Skåne University Hospital, Lund, Lund University, 22185 Lund, Sweden e-mail: kristina.vult_von_steyern@med.lu.se

I. M. Björkman-Burtscher Lund University Bioimaging Centre, Lund University, Lund, Sweden systems and is thus commonly considered to be the most significant finding when evaluating cystic fibrosis lung disease.

Teaching points

- Scoring of examinations is used for comparison of outcome in studies.

- Scoring of examinations can also be used for monitoring disease progression.

- Cystic fibrosis can be scored on radiography, tomosynthesis, CT or MRI.

-The typical imaging findings of cystic fibrosis depend on the imaging modality used.

- Bronchiectasis is commonly considered the most significant finding when scoring cystic fibrosis.

Keywords Cystic fibrosis · Magnetic resonance imaging · Radiography · Tomography, X-ray · Tomography, X-ray computed

\section{Introduction}

Radiological scoring systems for pulmonary cystic fibrosis have been introduced to allow for a standardised and robust comparison of radiological scoring to clinical scoring and for comparison of outcomes within patient groups in different studies. The evaluation of radiological studies is more objective when using a scoring system than simply describing the abnormal imaging findings.

Typical imaging features of cystic fibrosis are overinflation, bronchial wall thickening, bronchiectasis, mucus plugging, atelectasis and consolidation. In addition, abscesses, cysts, bullae, thickened inter- or intra-lobular septa, mosaic perfusion, ground glass opacities and air-trapping can be evaluated with 
computed tomography (CT). Radiography is often used to follow the development of pulmonary changes in cystic fibrosis, and to detect complications of the disease. CT is the modality which offers the best combination of high contrast resolution and detailed spatial resolution about the morphological findings in cystic fibrosis, but the role of CT is under investigation. It has up to now mainly been used for research purposes, due to the comparatively high radiation dose [1-3]. Recently tomosynthesis [4-6] and magnetic resonance imaging (MRI) [7-9] have appeared as alternatives to $\mathrm{CT}$ for more detailed evaluation of the pulmonary changes compared with radiography.

The first radiographic scoring system for pulmonary cystic fibrosis was presented by Shwachman and Kulczycki in 1958 [10]. Since then a multitude of scoring systems for radiography [11-21] and CT [22-35], and recently also scoring systems for tomosynthesis (digital tomography) [5] and MRI [9] have been presented. The aim of the current review was to analyse and compare the plethora of scoring systems for cystic fibrosis, with focus on the differences of the imaging modalities used and scoring components considered most important.

\section{Materials and methods}

\section{Selection of scoring systems}

From a survey of the literature and a search in PubMed (search terms: cystic fibrosis, scoring, system, radiography, computed tomography, tomosynthesis and MRI) followed by a manual perusal of references in the selected articles to locate all published scoring systems totally 28 scoring systems were found, 12 for radiography [10-21], one for tomosynthesis [5], 14 for CT [22-35] and one for MRI [9]. To select the most widely used scoring systems for the current review, scoring systems for radiography and $\mathrm{CT}$ with 25 or more citations in the Citation Index of the Web of Science database were selected for analysis. The scoring systems for tomosynthesis and MRI were published in 2012; consequently both systems yet have fewer citations in the Web of Science database.

Seven cystic fibrosis scoring systems for chest radiography with 25 or more citations were found in the Web of Science database, but the Shwachman-Kulczycki scoring system from 1958 [10], the National Institutes of Health (NIH) clinical score from 1973 [12] and the Royal Children's Hospital (RCH) pulmonary score from 1981 [14] were excluded since the scores are a part of clinical scores not included in this review and other authors have shown that the Brasfield score [11] is superior to those scoring systems $[36,37]$. Thus four radiography scoring systems remained for analysis: the Chrispin-Norman scoring system from 1974 [13] (with modifications 1982 [15] and 2005 [21]), the Brasfield scoring system from 1979 [11], the Wisconsin scoring system from 1993 [18] (with validation in 2000 [20]) and the Northern scoring system from 1994 [19].
Nine chest CT cystic fibrosis scoring systems with 25 or more citations were found in the Web of Science database, but the Brody I scoring system [29] was excluded from the comparison due to the development of the Brody II scoring system [34]. Thus, eight CT scoring systems remained for analysis: Bhalla [22] and Nathanson [23] from 1991, Maffessanti from 1996 [25], Shah from 1997 [27], Santamaria from 1998 [28], Helbich from 1999 [30, 38], Robinson from 2001 [32], and Brody II from 2004 [34] (Table 3). The scoring systems by Shah [27], Santamaria [28], Helbich [30], and Robinson [32] are developed from the Bhalla scoring system [22].

\section{Evaluated components}

The analysis of the scoring systems included an evaluation of: (1) The abnormalities scored such as increased lung volume, bronchial wall thickening, mucus plugging, bronchiectasis and parenchymal changes (e.g. atelectasis, consolidation, cysts and bullae) as well as the terminology used to describe these components; (2) the area scored for the components in each system (a general overview, evaluation per quadrant, per lobe, or per bronchopulmonary segment); (3) the number of scoring levels used for each component; (4) the weighting applied to each component as a percentage of the total score; (5) the calculations needed to reach the final score.

\section{Results}

The pulmonary abnormalities associated with cystic fibrosis have different appearances depending on the modality chosen to evaluate them (Fig. 1), and certain abnormalities can only be evaluated with $\mathrm{CT}$ or MRI, since CT has a higher contrast resolution than radiography and tomosynthesis and MRI is performed with intravenous contrast, enabling detection of perfusion defects (Table 1).

\section{Radiography}

Tables 2 and 3 give an overview of the four evaluated radiographic scoring systems. As the systems use two different scoring approaches, Table 2 shows one system based on integrated scores for lung areas and Table 3 shows three systems based on separate scoring components. In the modified Chrispin-Norman scoring system from 2005 [21], as well as in the Northern scoring system [19], only the frontal radiograph is needed for scoring.

\section{Scored abnormalities}

In all reviewed scoring systems for radiography (Tables 2 and 3), increased lung volume is scored separately, except in the Northern score [19] where it is included in the overall impression 

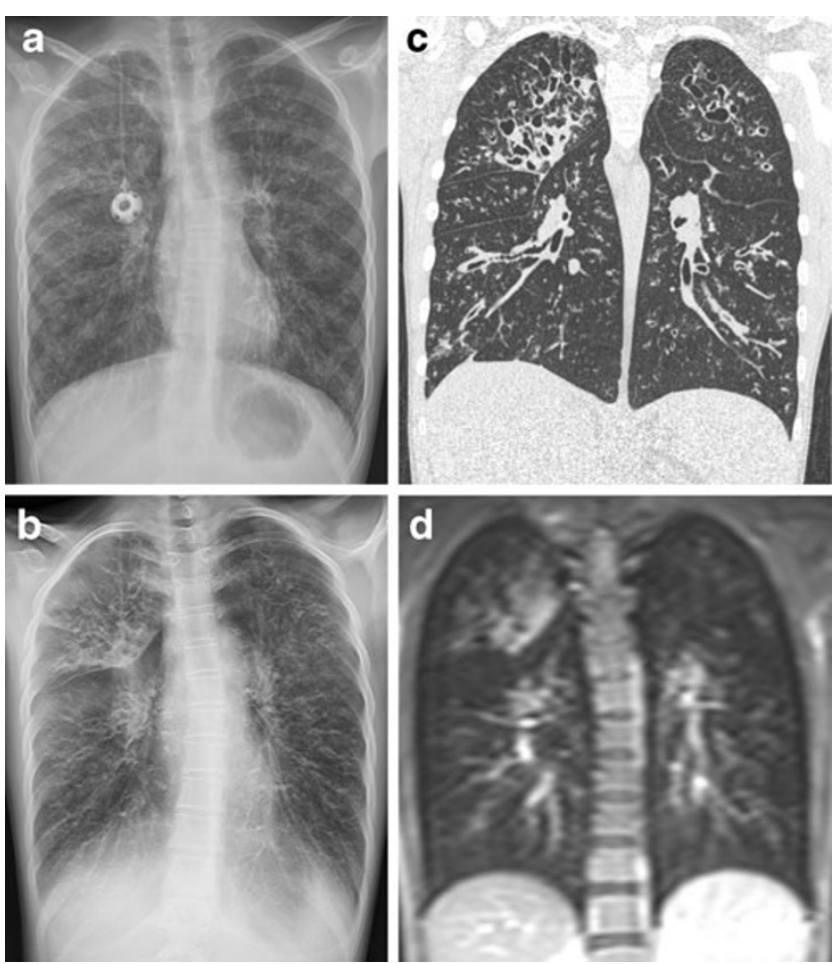

Fig. 1 A 15-year-old girl with cystic fibrosis examined with the four different imaging modalities within 4 months. A frontal radiograph (a) acquired on the same occasion as the tomosynthesis examination (b). CT (c) performed four months earlier and MRI (d) performed 2 weeks earlier (T1-weighted sequence, with intravenous contrast). Tomosynthesis, CT and MRI sections were selected to represent approximately the same imaging plane, to simplify the comparison between the modalities. Overinflation, bronchial wall thickening, bronchiectasis and mucus plugging were present in both lungs, with the most severe changes in the right upper lobe

score. Increased lung volume is described as altered chest configuration [13], air trapping [11], hyperinflation [15, 18, 20] or overinflation [21]. Bronchial wall thickening, evaluated in all scoring systems, is described as bronchial line shadows [13, 15], linear markings [11, 19] or peribronchial thickening [18, 20]. Bronchiectasis and mucus plugging are described as ring shadows and mottled shadows [13], as bronchiectasis and nodular-branching opacities [18], or scored together as nodular-cystic lesions [11, 19]. The parenchyma, evaluated in all scoring systems, is scored for large shadows [13], large lesions [11], large soft shadows [21], large round or ill-defined opacities [18], or collapse or consolidation [19]. In the Northern and the Brasfield scoring systems the overall [19] or general [11] severity is also scored, giving more flexibility according to the authors of the Northern scoring system as well as others [36].

\section{Scoring areas}

The Northern [19] scoring system (Table 2) gives an integrated score for all pulmonary abnormalities for each of the four lung quadrants. The other three systems [11, 13, 18] (Table 2) give separate scores for both lungs, central versus peripheral lung, lung zones, quadrants or lobes to each of the different pulmonary abnormalities such as increased lung volume, bronchial wall thickening, mucus plugging, bronchiectasis and large lesions.

\section{Scoring levels}

The Chrispin-Norman score [13] has three scoring levels (not present, present but not marked and marked) which are comparable to the Wisconsin scores [18] (none, mild, and severe) for bronchiectasis and nodular-branching opacities. In the Wisconsin score, large opacities are scored as absent or present, and then the numbers of affected lobes are rated. The other scoring systems predominately use five scoring levels.

\section{Weighting of components}

In the Chrispin-Norman [13] and the Wisconsin [18] scoring systems, the combination of bronchiectasis and mucus plugging is given the highest weighting in percentage of the total score (Table 7, Fig. 2). In the Wisconsin score, parenchymal changes are also given a high weighting. In the Brasfield score [11], large lesions and general severity are given the highest weightings, while bronchiectasis and mucus plugging are given comparatively low weightings.

\section{Calculations for final score}

The possible total scores for the evaluated scoring systems differ (Tables 2 and 3), as do the ways used to reach the final score; from simple addition to a complicated multiplicative [18] or additive [20] model.

\section{Tomosynthesis}

There is currently only one published scoring system for tomosynthesis, developed by Vult von Steyern et al. [5] (Table 4).

\section{Scored abnormalities and scoring areas}

Both lungs are scored for the degree of overinflation on the frontal and lateral radiographs, in comparison with reference images available on the publisher's web site. Each lung quadrant is scored for bronchial wall thickening, parenchymal lesions (atelectasis or consolidation), number and appearance of bronchiectatic bronchi and large $(>5 \mathrm{~mm})$ or small $(<5 \mathrm{~mm})$ mucus plugs, using all tomosynthesis sections covering the quadrant in question.

\section{Scoring levels}

The scoring components overinflation, parenchymal lesions, bronchiectasis and mucus plugging have five scoring levels $(0-4)$. Bronchial wall thickening has three scoring levels $(0-2-4)$. 
Table 1 A comparison of the four different radiological modalities regarding the ability to depict cystic fibrosis changes of the lungs (yes or no), as well as for cost; need for anaesthesia in young children; detail of information provided by the imaging modality; simplicity of the examination procedure; and radiation dose $[6,46,47]$. The approximate cost for each modality (derived from the price list of Skåne Regional Council, Sweden) was compared with the cost of a frontal and lateral radiograph, which was given the factor 1

\begin{tabular}{|c|c|c|c|c|c|}
\hline & & Radiography & Tomosynthesis & CT & MRI \\
\hline \multicolumn{6}{|l|}{ Evaluated abnormalities: } \\
\hline \multirow[t]{3}{*}{ Lung volume } & Increased lung volume & Yes & Yes & Yes & No \\
\hline & Emphysema & No & No & Yes & No \\
\hline & Air trapping (expiratory images) & No & No & Yes & No \\
\hline Bronchial wall thickening & & $(\text { Yes })^{\mathrm{a}}$ & Yes & Yes & $(\text { Yes })^{\mathrm{b}}$ \\
\hline Bronchiectasis & Mucus plugging/ radiography & $(\text { Yes })^{\mathrm{a}}$ & Yes & Yes & $(\text { Yes })^{b}$ \\
\hline Mucus plugging & & & Yes & Yes & Yes \\
\hline \multirow[t]{7}{*}{ Parenchyma } & Consolidation & Yes & Yes & Yes & Yes \\
\hline & Atelectasis & Yes & Yes & Yes & Yes \\
\hline & Cysts/Bullae & $(Y e s)^{\mathrm{a}}$ & Yes & Yes & $(Y e s)^{\mathrm{a}}$ \\
\hline & Abscesses & $(Y e s)^{\mathrm{a}}$ & Yes & Yes & Yes \\
\hline & Thickened intra-/inter-lobular septa & No & No & Yes & No \\
\hline & Mosaic perfusion & No & No & Yes & No \\
\hline & Ground glass opacities & No & No & Yes & No \\
\hline Pulmonary perfusion & & No & No & No & Yes \\
\hline Pleural affection & & Yes & Yes & Yes & Yes \\
\hline Cost, compared with radiography & & 1 & 1.1 & 5.5 & 10.7 \\
\hline Anaesthesia required for young children & & No & Yes & $(Y e s)^{c}$ & Yes \\
\hline Detail of information & & Low & Medium & High & Medium \\
\hline Quick and easy to perform & & Yes & Yes & $(\text { Yes })^{\mathrm{c}}$ & No \\
\hline Mean radiation dose $(\mathrm{mSv})$ & & $0.09-0.1$ & $0.12-0.13$ & $7-8$ & 0 \\
\hline
\end{tabular}

${ }^{a}$ Using radiography and MRI these changes are inferiorly discerned, compared with tomosynthesis and CT

${ }^{b}$ MRI cannot differentiate between bronchial wall thickening and bronchiectasis, especially in the lung periphery [9]

${ }^{c}$ Depending on the CT system used

The most severe score is 4 for all scoring components and subcomponents.

\section{Weighting of components}

The highest weighting is given bronchiectasis and mucus plugging, with $32 \%$ each of the maximum score (Table 7).

\section{Calculations for final score}

The maximum score is calculated by summation of the subscores, with a maximum total score of 100 .

\section{Computed tomography}

\section{Scored abnormalities}

Combined radiographic pathology, such as nodular-cystic lesions [11] and mottled and ring shadows [13], is resolved into more detail on chest $\mathrm{CT}$ and scored separately as mucus plugging and bronchiectasis in the CT scoring systems (Table 4).
Bronchial wall thickening is also seen more clearly on CT, corresponding to radiographic scoring terms such as bronchial line shadows [13] and linear markings [11]. Increased lung volume is scored as emphysema [22,30] or overinflation [25]. Three of the CT scoring systems score air trapping on expiratory images $[28,32,34]$ (in the current review this scoring component has been included in the score for increased lung volume). The Nathanson CT scoring system [23] scores only bronchiectasis and mucus plugging. The other chest CT scoring systems all evaluate bronchial wall thickening, bronchiectasis, mucus plugging and parenchymal lesions, with the exception of the Maffessanti system [25], where mucus plugging is regarded as a transient phenomenon and recorded separately from the total score. Sacculations and abscesses are scored in the Bhalla [22] and the Helbich [30] scoring systems. In the Shah scoring system [27], air-fluid levels and centrilobular nodules are scored. In the Santamaria [28] and the Brody II [34] systems, ground glass opacities are scored either separately or as a part of the parenchyma score. In the Santamaria scoring system [28], thickening of intra- and interlobular septa as well as acinar nodules or consolidations are 
Table 2 An overview of the Northern scoring system [19], adapted from the original publication

\begin{tabular}{lll}
\hline Radiography scoring system & Northern (1994) [19] & \\
\cline { 2 - 3 } & Comment & Score (points) \\
\hline Scoring area & 4 lung quadrants & $0-4$ \\
Scoring & Both lungs (overall severity) & $0-4$ \\
& No cystic fibrosis lung disease evident & \\
& Minimal increase in linear markings and/or nodular & Normal (0) \\
& cystic lesions up to 0.5 cm diameter & Mild (1) \\
& More pronounced linear markings and/or more & Moderate (2) \\
widespread nodular cystic lesions & Prominent increase in linear markings, profuse nodular \\
cystic lesions, large areas of collapse/consolidation & Severe (3) \\
Little or no area of normal lung seen, dense infiltration & Very severe (4) \\
Overall severity & & Range 0-4 \\
Total score & & Maximum 20 \\
\hline
\end{tabular}

scored. The Helbich system [30] scores mosaic perfusion (Table 5).

\section{Scoring areas}

The chest CT scoring systems score the abnormalities per bronchopulmonary segment [22, 27, 28, 30], 12 zones [23], six lobes [27, 32, 34] or four regions [25]. In the Bhalla [22], the Santamaria [28] and the Helbich [30] scoring systems, bronchiectasis is scored both for severity, extent (number of bronchopulmonary segments involved) and for number of generations of bronchial divisions involved (this score component also includes mucus plugging). In the Maffessanti scoring system [25], bronchiectasis and bronchial wall thickening are scored for severity and extent (central, intermediate, to peripheral lung), and then the percentage of regional involvement is assessed both for the bronchial score and for the parenchyma score. In the Brody II scoring system [34], bronchiectasis and peribronchial thickening are scored for severity and extent (central to peripheral lung).

\section{Scoring levels}

In the scoring systems for $\mathrm{CT}$ most components are scored using four grades (0-3). In the Nathanson [23] scoring system, six grades are used for scoring bronchiectasis, and mucus plugging is scored as absent or present. In the Robinson [32] scoring system, five grades are used for all components.

\section{Weighting of components}

In the majority of the CT scoring systems the highest weighting in percentage of the total score is given bronchiectasis, except in the Robinson [32] and Santamaria [28] scoring systems. In the Robinson scoring system [32], all scoring components are given the same weighting $(20 \%)$, and in the Santamaria system [28] parenchymal changes are given the highest weighting $(43 \%)$. Bronchiectasis together with mucus plugging is given the highest weighting in all scoring systems, except in the Santamaria system, and the parenchymal abnormalities are given a relatively high weighting in many scoring systems (Table 7, Fig. 2). However, the range of the weighting of components in the scoring systems is wide (Table 7).

\section{Calculations for final score}

As for radiography, the final scores for $\mathrm{CT}$ are also arrived at by means of varying degrees of complicated mathematics, ranging from simple additive scores to the Brody II score [34], where a theoretical maximum of 243 points cannot be greater than 207, and the resultant score is normalised to a grading from 0 to 100 .

\section{MRI}

As for tomosynthesis, there is currently only one published scoring system for MRI, developed by Eichinger et al. [9] (Table 6).

\section{Scored abnormalities and scoring areas}

Six lung lobes (the lingula is considered a single lobe) are scored for bronchiectasis/wall thickening, mucus plugging, abscess/sacculation, consolidation, special findings and perfusion defect size (after intravenous contrast). Bronchiectasis and bronchial wall thickening are scored as a single entity since the spatial resolution of MRI does not allow for differentiation between them. Special findings relate to pleural affection, reflecting for example pleural effusion, pleural reaction/pleurisy or pneumothorax [9]. 
Table 3 An overview of three scoring systems for chest radiography in cystic fibrosis, adapted from the original publications. The modification of the Chrispin-Norman score from 1982 [19] also included enlarged hilar lymph nodes in the score, in this table included in the parenchyma score.
In the Wisconsin scoring system [18] each scoring component is weighted, the range for each component score was calculated by using the formula given in the publication

\begin{tabular}{|c|c|c|c|}
\hline Radiography scoring systems & $\begin{array}{l}\text { Chrispin-Norman (1974) [13] } \\
\text { Modified } 1982 \text { [15] Modified 2005 [21] }\end{array}$ & $\begin{array}{l}\text { Brasfield } \\
(1979)[11]\end{array}$ & $\begin{array}{l}\text { Wisconsin (1993) } \\
\text { [18] Validated } 2000 \text { [20] }\end{array}$ \\
\hline Scoring area & 4 zones & Both lungs & $\begin{array}{l}\text { - central/peripheral } \\
\text { (peribronchial thickening) } \\
\text { - } 4 \text { quadrants (bronchiectasis, } \\
\text { nodules) } \\
\text { - } 5 \text { lobes (opacities, atelectasis) }\end{array}$ \\
\hline \multicolumn{4}{|c|}{ Scoring components/scoring levels, scoring range } \\
\hline Increased lung volume & $\begin{array}{l}\text { Chest configuration [13] } \\
\text { - Sternal bowing } \\
\text { - Diaphragm depression } \\
\text { - Spinal kyphosis } \\
\text { Overinflation [21] } \\
\text { - Diaphragm depression } \\
\text { - Chest wall shape } \\
\text { - Lung fields } \\
\text { Each finding is scored 0-2 } \\
\text { Range } \mathbf{0}-\mathbf{6}\end{array}$ & $\begin{array}{l}\text { Air trapping } \\
\text { - sternal bowing } \\
\text { - depression of diaphragm } \\
\text { - and/or thoracic kyphosis } \\
\text { 0-4 } \\
\text { Range 0-4 }\end{array}$ & $\begin{array}{l}\text { Hyperinflation } \\
\text { - diaphragm contour } \\
\text { - retrosternal lucency } \\
\text { - heart position } \\
\text { - sternal bowing } \\
\text { - kyphosis } \\
\text { 0-1 } \\
\text { (Range 0-12.5) }\end{array}$ \\
\hline Bronchial wall thickening & $\begin{array}{l}\text { Bronchial line shadows } \\
\text { Each zone 0-2 } \\
\text { Range } 0-8\end{array}$ & $\begin{array}{l}\text { Linear markings } \\
0-4 \\
\text { Range 0-4 }\end{array}$ & $\begin{array}{l}\text { Peribronchial thickening } \\
\text { 0-1 } \\
\text { (Range 0-12.5) }\end{array}$ \\
\hline Bronchiectasis and mucus plugging & $\begin{array}{l}\text { - Ring shadows } \\
0-2 \\
\text { - Mottled shadows } \\
\text { 0-2 } \\
\text { Range } 0 \text { - } 16\end{array}$ & $\begin{array}{l}\text { Nodular cystic lesions } \\
\mathbf{0}-\mathbf{4} \\
\text { Range } \mathbf{0}-\mathbf{4}\end{array}$ & $\begin{array}{l}\text { - Bronchiectasis } \\
0-1 \\
\text { (Range } 0-31 \text { ) } \\
\text { - Nodular branching opacities } \\
0-1 \\
(\text { Range } 0-12.5)\end{array}$ \\
\hline Parenchyma & $\begin{array}{l}\text { Large shadows } \\
\text { Each zone } 0-2 \\
\text { Range 0-8 } \\
(\text { Enlarged hilar shadows }[15] \\
0-2 \times 2 \\
\text { Range } 0-4)\end{array}$ & $\begin{array}{l}\text { Large lesions } \\
\mathbf{0}-\mathbf{5} \\
\text { Range } \mathbf{0}-\mathbf{5}\end{array}$ & $\begin{array}{l}\text { - Large opacities } \\
\mathbf{0}-\mathbf{1} \\
(\text { Range } 0-12.5) \\
\text { - Atelectasis } \\
0-1 \\
(\text { Range } 0-19)\end{array}$ \\
\hline Overall severity & & $\begin{array}{l}0-5 \\
\text { Range } 0-5\end{array}$ & \\
\hline Total score & $\begin{array}{l}\text { Maximum } 38[13,21] \\
\text { Maximum } 42[15]\end{array}$ & Maximum 22 & $\begin{array}{l}\text { Maximum } 100 \text { p } \\
\text { - Multiplicative model [18] } \\
\text { - Additive model [20] }\end{array}$ \\
\hline
\end{tabular}

\section{Scoring levels}

The scoring levels $0-1-2$ are used for all parameters, where 1 implies involvement of less than 50\% of the lobe and 2 implies involvement of more than $50 \%$ of the lobe.

\section{Weighting of components}

All components of the score are given the same weighting, $17 \%$ of the maximum score (Table 7 ).

\section{Calculations for final score}

The maximum score is calculated by summation of the subscores, with a maximum score of 12 per lobe and a maximum total score of 72 .

\section{Discussion}

The evolution of radiological scoring systems for pulmonary cystic fibrosis reflects a desire to translate the pathological 


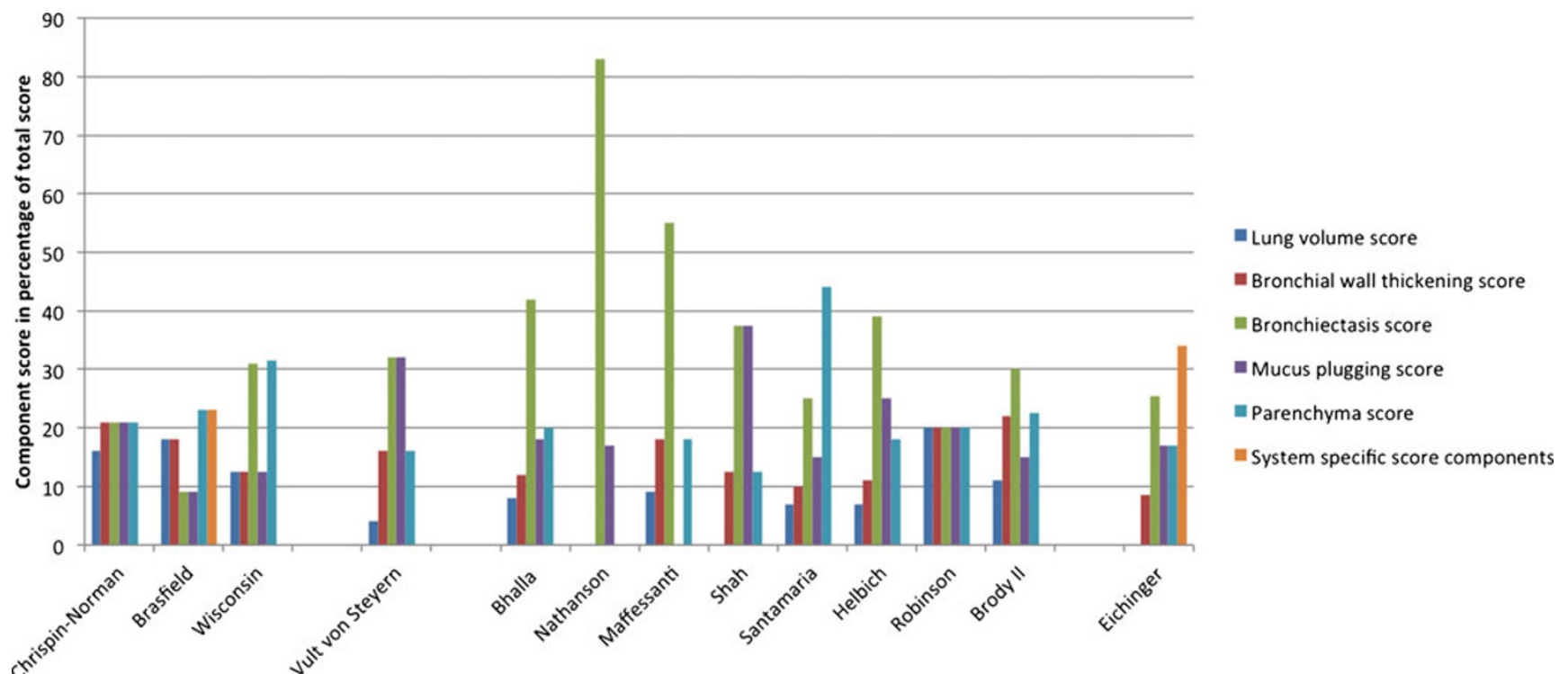

Fig. 2 A comparison of the weighting of scoring components (percentage of total score) in three radiographic scoring systems [11, 13, 18], one tomosynthesis scoring system [5], eight CT scoring systems [22, 23, 25, $27,28,30,32,34]$, and one MRI scoring system [9]. The Brasfield system [11] scores bronchiectasis and mucus plugging together as "nodular cystic

findings in the images into numbers, in a reproducible and objective way. Clinicians are of course interested in the general disease progression, but also in the progression of a separate component, such as mucus plugging, atelectasis or

Table 4 An overview of the scoring system for tomosynthesis presented by Vult von Steyern et al. [5], adapted from the original publication

Tomosynthesis scoring system Vult von Steyern [5] (2012)

\begin{tabular}{|c|c|}
\hline Scoring area & $\begin{array}{l}\text { Overinflation: both lungs } \\
\text { Other components: } 4 \text { quadrants }\end{array}$ \\
\hline \multicolumn{2}{|c|}{ Scoring components/scoring levels, scoring range } \\
\hline Increased lung volume & $\begin{array}{l}\text { Overinflation, overall impression } \\
0-4 \text {, Range 0-4 }\end{array}$ \\
\hline Bronchial wall thickening & Each quadrant $0-2-4$, Range $0-16$ \\
\hline Bronchiectasis & $\begin{array}{l}\text {-Number of bronchiectasis } \\
\text { Each quadrant } 0-4, \text { Range } 0-\mathbf{1 6} \\
\text {-Appearance of widest bronchiectasis } \\
\text { Each quadrant } 0-\mathbf{4} \text {, Range } \mathbf{0}-\mathbf{1 6}\end{array}$ \\
\hline Mucus plugging & $\begin{array}{l}\text {-Large mucus plugs } \\
\text { Each quadrant } 0-4 \text {, Range } 0-16 \\
\text {-Small mucus plugs } \\
\text { Each quadrant } 0-4 \text {, Range } 0-16\end{array}$ \\
\hline Parenchyma & $\begin{array}{l}\text { Atelectasis or consolidation } \\
\text { Each quadrant } 0-4, \text { Range 0-16 }\end{array}$ \\
\hline Total score & Maximum 100 (sum of subscores) \\
\hline
\end{tabular}

lesions", and in the MRI score bronchiectasis and bronchial wall thickening are scored together. In this table these scores are divided between the two entities. "System specific score components" refer to general severity in the Brasfield score [11], and special findings and perfusion size in the MRI score [9]

consolidation since treatment then can be focused on a specific pathology with a specific therapy. Chest radiography is the most widely used imaging modality to track the progression of cystic fibrosis lung disease, since it is easy to perform and the radiation dose and cost are low. Scoring systems for tomosynthesis, CT and MRI are still mainly used for research purposes. The different modalities obviously have different abilities to detect cystic fibrosis changes, but when deciding which modality to choose in the follow-up of patients with cystic fibrosis other aspects are of course also important, such as radiation dose, cost and the possibility to perform the examination on young children without anaesthesia (Fig. 1, Table 1).

Figures from studies using different radiological scoring systems are difficult to compare, due to the different scoring components and scoring areas used by the scoring systems, and also from divergences in weighting and terminology. For example, "bronchial wall thickening" [25, 29] may also be called "bronchial line shadows" [13], "linear markings" [11, 19] or "peribronchial thickening" [18, 34]. Chest CT and tomosynthesis obviously have a greater ability to detect early abnormalities that may have similar appearances on radiography, there reflected in radiographic scoring terms such as "nodular cystic lesions" [11, 19], whereas CT and tomosynthesis scoring systems may differentiate these lesions into "mucus plugging" and "bronchiectasis". MRI, on the other hand, is more sensitive to mucus plugging compared with CT [8], but cannot evaluate air trapping or differentiate 


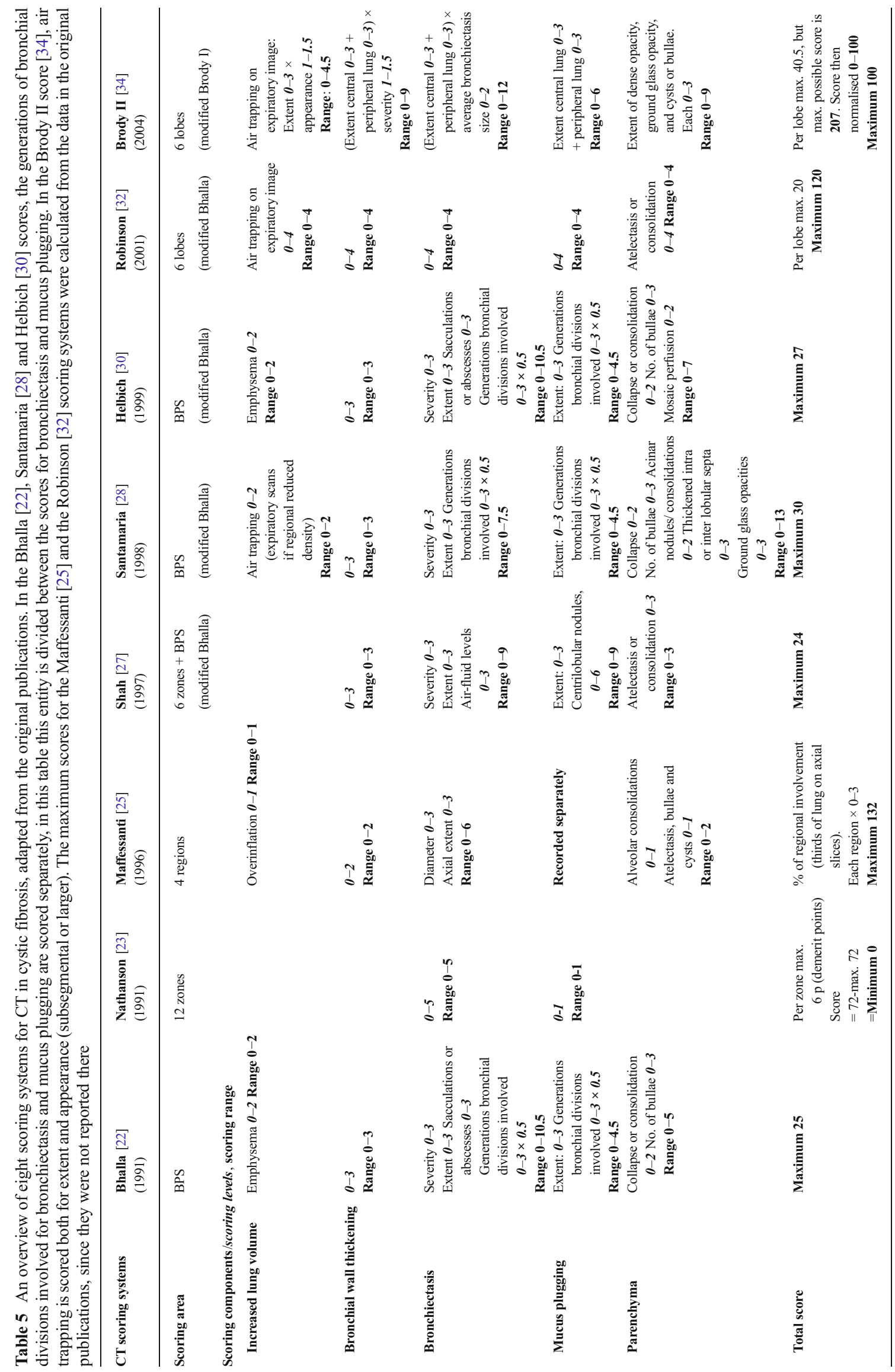


Table 6 An overview of the scoring system for MRI presented by Eichinger et al. [9], adapted from the original publication

\begin{tabular}{ll}
\hline MRI scoring system & Eichinger [9] (2012) \\
\hline $\begin{array}{l}\text { Scoring area } \\
\text { Scoring components/scoring levels }\end{array}$ & , scoring range \\
Bronchiectasis/ & Each lobe $0-1-2$, range 0-12 \\
wall thickening & \\
Mucus plugging & Each lobe $0-1-2$, range 0-12 \\
Abscesses/sacculations & Each lobe $0-1-2$, range 0-12 \\
Consolidation & Each lobe $0-1-2$, range 0-12 \\
Perfusion size & Each lobe $0-1-2$, range 0-12 \\
Total score & Maximum 72 (sum of subscores) \\
\hline
\end{tabular}

between bronchial wall thickening and bronchiectasis [9] (Table 1).

In most scoring systems, increased lung volume, bronchial wall thickening, bronchiectasis, mucus plugging and parenchymal changes are scored (Fig. 2). In some CT scoring systems, air trapping on expiratory images and mosaic perfusion are evaluated. Sacculations and abscesses are scored together in two CT scoring systems as well as on MRI, as the image resolution often does not often allow for differentiation between these entities (sacculations are dilated bronchi and abscesses are located in the lung parenchyma). In addition, some CT scoring systems score for cysts/bullae, ground glass opacities and thickened intra- or inter-lobular septa. In the MRI score, pleural affection is scored as a special finding and a functional scoring component has been introduced, as first-pass perfusion images are assessed, making it possible to evaluate perfusion defects (which is an unique scoring component for the MRI) scoring system), which according to preliminary results from on-going studies may allow differentiation between reversible and irreversible lung changes [7].

For all scoring systems, a defined total score which should represent the total structural lung damage has been reported in the articles, except for the scoring systems of Maffessanti [25] and Robinson [32]. It has been shown that inter-observer reproducibility is higher for the total score than for the component scores for most CT scoring systems [39] as well as for the tomosynthesis scoring system [5].

The range of the weightings, expressed as the component score in percentage of the total score, is wide (Table 7, Fig. 2), indicating disagreement between research groups on which abnormalities are the most indicative of changes in disease status. Bronchiectasis and mucus plugging are the most specific pulmonary abnormalities for cystic fibrosis $[15,40]$ and some authors have even suggested that selective scoring of mucus plugging and bronchiectasis might be as sensitive as more complicated CT scoring systems in observing the course of disease in patients with cystic fibrosis [23, $35,40,41]$. It is therefore logical to give them a high score compared with other findings, and most scoring systems give bronchiectasis alone, or in combination with mucus plugging, the highest weightings. Bronchiectasis is generally given higher weightings in $\mathrm{CT}$ and MRI scoring systems (when combined with scores for abscess and sacculation), as well as in the tomosynthesis scoring system, compared with radiographic scoring systems (Table 7, Fig. 2), probably due to the fact that bronchiectasis is more clearly visualised. The mean scores for mucus plugging $(17 \%)$ are the same for radiography, CT and MRI scoring systems, even though CT and MRI depict these changes better than radiography, but is higher in the tomosynthesis scoring system (32\%), where the sum of the scores for mucus plugging together with bronchiectasis contribute to $64 \%$ of the total score.

In the current review, the term "increased lung volume" has been used in place of the not exactly interchangeable terms "overinflation" and "air trapping". Air trapping can only be evaluated on expiratory CT scans, and overinflation would in most cases be the more appropriate term, when expiratory images are not used. Bronchial wall thickening and increased lung volume are commonly seen in cystic fibrosis but are nonspecific abnormalities that can often be seen in, for example, children with asthma and bronchiolitis, and in most scoring systems these components are consequently given quite low weightings in percentage of the total score (Table 7, Fig. 2). Consolidations and atelectasis of the parenchyma are also non-specific and are in most scoring systems given a weighting of about $20 \%$ of the total score. However, in the CT scoring systems of Santamaria [28], Robinson [32] and Brody [34] expiratory images are included, as air trapping in these scoring systems is thought to reflect small airway disease in early cystic fibrosis [40, 42].

In a comparison of six radiography scoring systems with correlation to clinical parameters by Terheggen-Lagro et al. [43], the authors concluded that all six scoring systems correlated well with lung function tests and infectious exacerbation rate, showed low inter-observer variation and that a simple scoring system like the Chrispin-Norman system was preferable. In a European consensus paper on standards of care for patients with cystic fibrosis in 2005 [44] the authors recommended the use of the Northern scoring system for radiography, since it only requires the frontal projection for scoring. Five CT scoring systems have been validated in a previous study [39] and, despite differences in scoring and weighting, the authors found no differences in the scoring systems' ability to track disease progression in 48 children [40, 41]. In a study by Puderbach et al. [45], 31 patients with cystic fibrosis were examined with MRI, radiography and CT, and using a modified ChrispinNorman score [13] for radiography and a modified Helbich score [30] for CT and MRI the authors found comparable results for all modalities. 


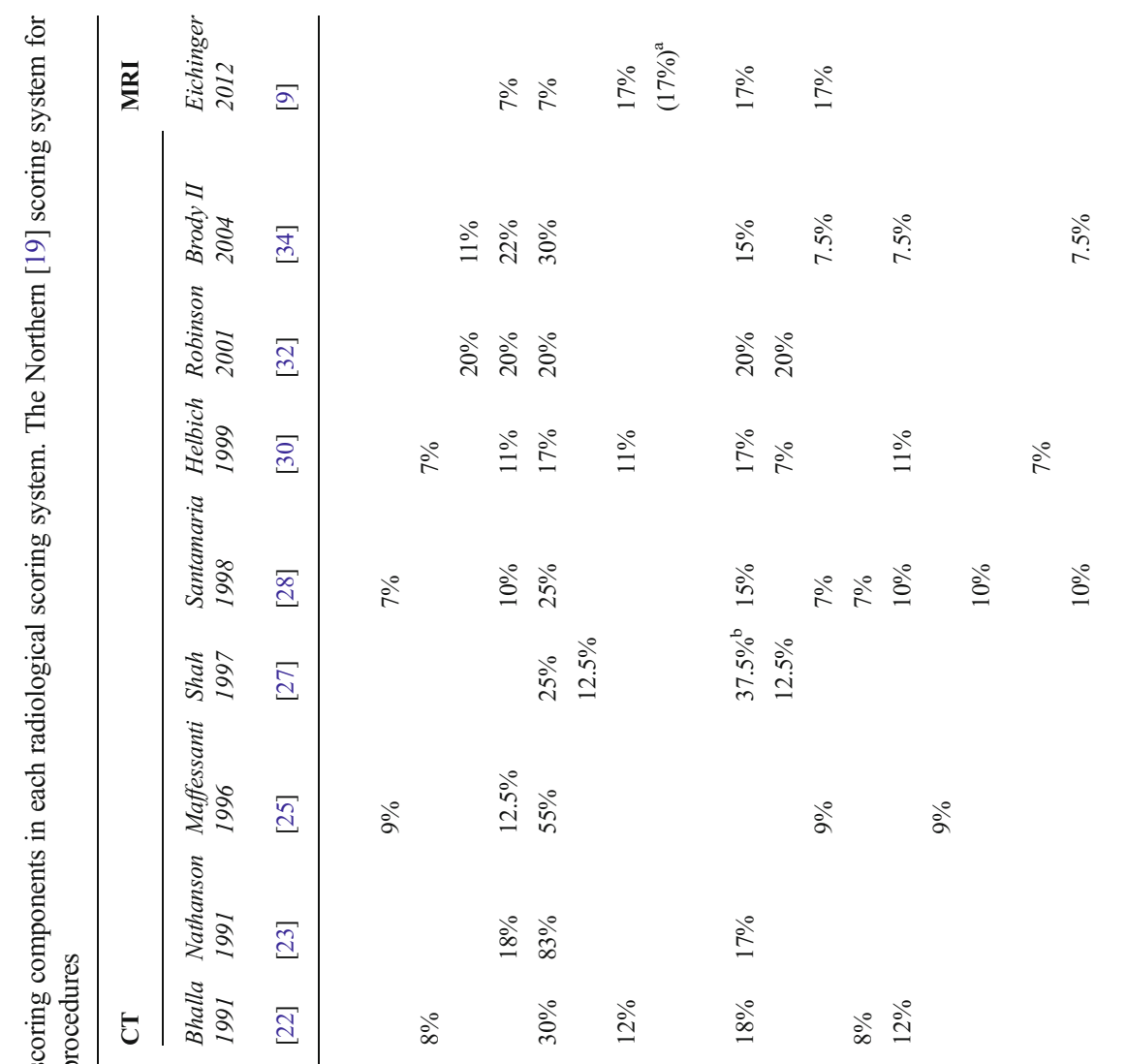

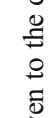$$
\text { 离 }
$$$$
\text { 边: }
$$$$
\text { 퓽 }
$$

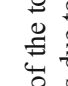

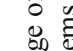

$$
\text { 焉 }
$$

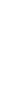


Radiography is an easily accessible modality, with low cost and radiation dose [46, 47], but the diagnostic detail is low (Table 1). Tomosynthesis is superior to radiography in the detection of cystic fibrosis changes [4, 5], and also has the advantages of low cost and radiation dose [6], but cannot be performed in young children without anaesthesia (since a breath-hold of $10 \mathrm{~s}$ is required). MRI is an interesting alternative in the follow-up and monitoring of cystic fibrosis, since it is performed without radiation and offers the possibility of scoring perfusion [7-9], but is expensive and also requires anaesthesia for young children. CT remains the "gold standard", but has the disadvantage of a high radiation dose [46, 47]. Alternative $C T$ imaging protocols are under development, with lower dose than conventional settings [48], but the reported effective dose still is higher than for radiography and tomosynthesis [6, 46, 47].

In conclusion, to try to objectify the progression of cystic fibrosis lung disease different imaging modalities can be used, with specific advantages and disadvantages. A multitude of scoring systems have been proposed for radiography and CT, and recently scoring systems for tomosynthesis and MRI also have been presented. There are large divergences in the radiological scoring systems. Most scoring systems, however, consider bronchiectasis alone, or in combination with mucus plugging, to be the most important component of the score. Bronchiectasis, with or without mucus plugging, is thus the most significant finding when evaluating pulmonary cystic fibrosis.

Conflicts of interest The authors declare no conflicts of interest. No funding was received for this work.

Open Access This article is distributed under the terms of the Creative Commons Attribution License which permits any use, distribution, and reproduction in any medium, provided the original author(s) and the source are credited.

\section{References}

1. Aziz ZA, Davies JC, Alton EW, Geddes DM, Hansell DM (2007) Computed tomography and cystic fibrosis: promises and problems. Thorax 62:181-186

2. Cooper P, MacLean J (2006) High-resolution computed tomography (HRCT) should not be considered as a routine assessment method in cystic fibrosis lung disease. Paediatr Respir Rev 7:197-201

3. Tiddens H (2006) Chest computed tomography scans should be considered as a routine investigation in cystic fibrosis. Paediatr Respir Rev 7:202-208

4. Vult von Steyern K, Björkman-Burtscher I, Geijer M (2012) Tomosynthesis in pulmonary cystic fibrosis with comparison to radiography and computed tomography: a pictorial review. Insights Imaging 3:81-89

5. Vult von Steyern K, Björkman-Burtscher IM, Höglund P, Bozovic G, Wiklund M, Geijer M (2012) Description and validation of a scoring system for tomosynthesis in pulmonary cystic fibrosis. Eur Radiol 22: 2718-2728
6. Båth M, Svalkvist A, von Wrangel A, Rismyhr-Olsson H, Cederblad $\AA$ (2010) Effective dose to patients from chest examinations with tomosynthesis. Radiat Prot Dosim 139:153-158

7. Eichinger M, Puderbach M, Fink C et al (2006) Contrast-enhanced 3D MRI of lung perfusion in children with cystic fibrosis-initial results. Eur Radiol 16:2147-2152

8. Puderbach M, Eichinger M, Gahr J et al (2007) Proton MRI appearance of cystic fibrosis: comparison to CT. Eur Radiol 17:716-724

9. Eichinger M, Optazaite D-E, Kopp-Schneider A et al (2012) Morphologic and functional scoring of cystic fibrosis lung disease using MRI. Eur J Radiol 81:1321-1329

10. Shwachman H, Kulczycki L (1958) Long-term study of one hundred five patients with cystic fibrosis: studies made over a five-to fourteenyear period. AMA J Dis Child 96:6-15

11. Brasfield D, Hicks G, Soong S, Tiller RE (1979) The chest roentgenogram in cystic fibrosis: a new scoring system. Pediatrics 63:24-29

12. Taussig L, Kattwinkel J, Friedewald W, Di Sant'Agnese PA (1973) A new prognostic score and clinical evaluation system for cystic fibrosis. J Pediatr 82:380-390

13. Chrispin A, Norman A (1974) The systematic evaluation of the chest radiograph in cystic fibrosis. Pediatr Radiol 2:101-105

14. Holzer F, Olinsky A, Phelan P (1981) Variability of airways hyperreactivity and allergy in cystic fibrosis. Arch Dis Child 56:455-459

15. Van der Put J, Meradji M, Danoesastro D, Kerrebijn KF (1982) Chest radiographs in cystic fibrosis. A follow-up study with application of a quantitative system. Pediatr Radiol 12:57-61

16. Carty H (1987) The chest radiograph in cystic fibrosis in children and the role of other radiological techniques. J R Soc Med 80:38-46

17. O'Laoide R, Fahy J, Coffey M et al (1991) A chest radiograph scoring system in adult cystic fibrosis: Correlation with pulmonary function. Clin Radiol 43:308-310

18. Weatherly M, Palmer C, Peters M et al (1993) Wisconsin cystic fibrosis chest radiograph scoring system. Pediatrics 91:488-495

19. Conway S, Pond M, Bowler I et al (1994) The chest radiograph in cystic fibrosis: a new scoring system compared with the ChrispinNorman and Brasfield scores. Thorax 49:860-862

20. Koscik R, Kosorok M, Farrell P et al (2000) Wisconsin cystic fibrosis chest radiograph scoring system: validation and standardization for application to longitudinal studies. Pediatr Pulmonol 29:457-467

21. Benden C, Wallis C, Owens C, Ridout DA, Dinwiddie R (2005) The Chrispin-Norman score in cystic fibrosis: doing away with the lateral view. Eur Respir J 26:894-897

22. Bhalla M, Turcios N, Aponte V et al (1991) Cystic fibrosis: scoring system with thin-section CT. Radiology 179:783-788

23. Nathanson I, Conboy K, Murphy S, Afshani E, Kuhn JP (1991) Ultrafast computerized tomography of the chest in cystic fibrosis: a new scoring system. Pediatr Pulmonol 11:81-86

24. Stiglbauer R, Schurawitzki H, Eichler I, Vergesslich KA, Götz M (1992) High resolution CT in children with cystic fibrosis. Acta Radiol 33:548-553

25. Maffessanti M, Candusso M, Brizzi F, Piovesana F (1996) Cystic fibrosis in children: HRCT findings and distribution of disease. J Thorac Imaging 11:27-38

26. Donnelly L, Gelfand MJ, Brody AS, Wilmott RW (1997) Comparison between morphologic changes seen on high-resolution $\mathrm{CT}$ and regional pulmonary perfusion seen on SPECT in patients with cystic fibrosis. Pediatr Radiol 27:920-925

27. Shah R, Sexauer W, Ostrum B, Fiel SB, Friedman AC (1997) Highresolution $\mathrm{CT}$ in the acute exacerbation of cystic fibrosis: evaluation of acute findings, reversibility of those findings, and clinical correlation. AJR Am J Roentgenol 169:375-380

28. Santamaria F, Grillo G, Guidi G et al (1998) Cystic fibrosis: when should high-resolution computed tomography of the chest be obtained? Pediatrics 101:908-913

29. Brody A, Molina P, Klein J, Rothman BS, Ramagopal M, Swartz DR (1999) High-resolution computed tomography of the chest in 
children with cystic fibrosis: support for use as an outcome surrogate. Pediatr Radiol 29:731-735

30. Helbich T, Heinz-Peer G, Eichler I et al (1999) Cystic fibrosis: CT assessment of lung involvement in children and adults. Radiology 213:537-544

31. Castile R, Hayes J, Flucke R, McCoy KS (2000) Correlation of structural and functional abnormalities in the lungs of infants with cystic fibrosis (Abstract). Pediatr Pulmonol 20:A427

32. Robinson T, Leung A, Northway W et al (2001) Spirometer-triggered high-resolution computed tomography and pulmonary function measurements during an acute exacerbation in patients with cystic fibrosis. J Pediatr 138:553-559

33. Oikonomou A, Manavis J, Karagianni P et al (2002) Loss of FEV1 in cystic fibrosis: correlation with HRCT features. Eur Radiol 12:2229-2235

34. Brody A, Klein J, Molina P, Quan J, Bean JA, Wilmott RW (2004) High-resolution computed tomography in young patients with cystic fibrosis: distribution of abnormalities and correlation with pulmonary function tests. J Pediatr 145:32-38

35. Oikonomou A, Tsanakas J, Hatziagorou E et al (2008) High resolution computed tomography of the chest in cystic fibrosis (CF): is simplification of scoring systems feasible? Eur Radiol 18:538-547

36. Wong E, Regnis J, Shnier R, Bye PT, Stewart ME (1993) The relationship between tests of lung function and three chest radiological scoring systems in patients with cystic fibrosis. Australas Radiol 37:265-269

37. Sawyer S, Carlin J, DeCampo M, Bowes G (1994) Critical evaluation of three chest radiograph scores in cystic fibrosis. Thorax 49:863-866

38. Helbich T, Heinz-Peer G, Fleischmann D et al (1999) Evolution of CT findings in patients with cystic fibrosis. AJR Am J Roentgenol 173:81-88

39. de Jong P, Ottink M, Robben S et al (2004) Pulmonary disease assessment in cystic fibrosis: comparison of CT scoring systems and value of bronchial and arterial dimension measurements. Radiology 231:434-439

40. de Jong P, Tiddens H (2007) Cystic fibrosis specific computed tomography scoring. Proc Am Thorac Soc 4:338-342

41. De Jong P, Nakano Y, Lequin M et al (2004) Progressive damage on high resolution computed tomography despite stable lung function in cystic fibrosis. Eur Respir J 23:93-97

42. Bonnel AS, Song SM, Kesavarju K et al (2004) Quantitative airtrapping analysis in children with mild cystic fibrosis lung disease. Pediatr Pulmonol 38:396-405

43. Terheggen-Lagro S, Truijens N, van Poppel N, Gulmans V, van der Laag J, van der Ent C (2003) Correlation of six different cystic fibrosis chest radiograph scoring systems with clinical parameters. Pediatr Pulmonol 35:441-445

44. Kerem E, Conway S, Elborn S, Heijerman H (2005) Standards of care for patients with cystic fibrosis: a European consensus. J Cyst Fibros 4:7-26

45. Puderbach M, Eichinger M, Haeselbarth J et al (2007) Assessment of morphological MRI for pulmonary changes in cystic fibrosis (CF) patients: comparison to thin-section $\mathrm{CT}$ and chest X-ray. Invest Radiol 42:715-724

46. Smith-Bindman R, Lipson J, Marcus R et al (2009) Radiation dose assosiated with common computed tomography examinations and the associated lifetime attributable risk of cancer. Arch Intern Med 169:2078-2086

47. Mettler FA, Huda W, Yoshizumi TT, Mahesh M (2008) Effective doses in radiology and diagnostic nuclear medicine: a catalog. Radiology 24:254-263

48. Loeve M, Lequin MH, de Bruijne M et al (2009) Cystic fibrosis: are volumetric ultra-low-dose expiratory CT scans sufficient for monitoring related lung disease? Radiology 253:223-229 